Supporting Information

\title{
Synthesis and Unimolecular ESA-CF Polymer Cyclization of Zwitterionic Telechelic Precursors
}

Tsuneaki Konomoto, Koji Nakamura, Takuya Yamamoto ${ }^{+}$and Yasuyuki Tezuka*

\begin{abstract}
Department of Organic and Polymeric Materials, Tokyo Institute of Technology, O-okayama,
\end{abstract}
Meguro-ku, Tokyo 152-8552, Japan

*Address corresponding to this author: ytezuka@o.cc.titech.ac.jp, ytezukak33@gmail.com

${ }^{+}$Current Address; Division of Applied Chemistry, Faculty of Engineering, Hokkaido University,

Sapporo, Hokkaido, 060-8628, Japan. 


\section{EXPERIMENTAL SECTION}

Synthesis of a telechelic polystyrene having a hydroxyl and a methyl carboxylate groups

(PS-1).

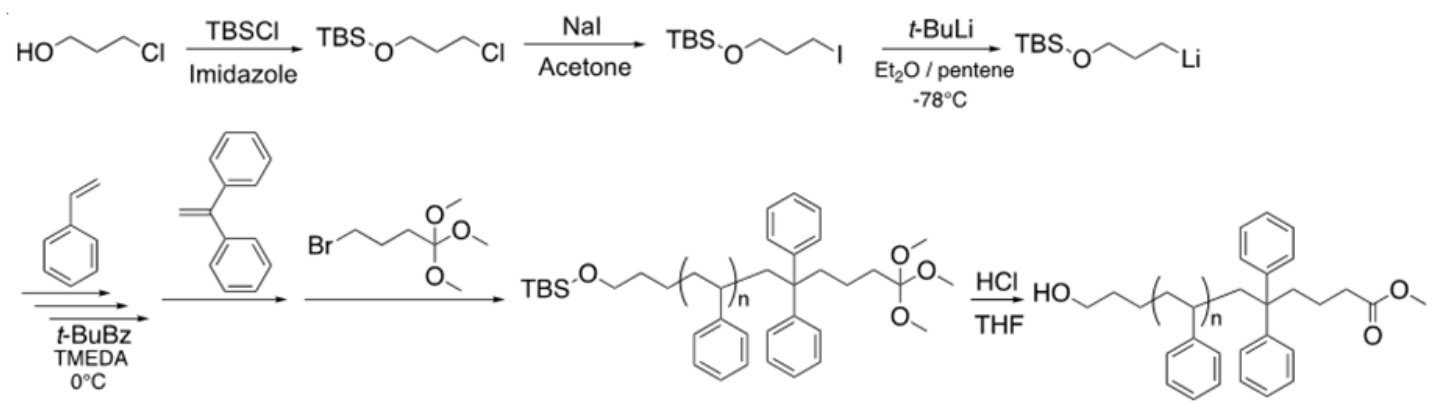

Firstly, 3-iodopropoxy-tert-butyldimethylsilane was synthesized as a precursor to prepare

an initiator. ${ }^{1,2}$ Thus, a DMF solution $(40 \mathrm{~mL})$ containing tert-butyldimethylsilylchloride (14.3

g, $94.9 \mathrm{mmol})$ and imidazole $(7.8 \mathrm{~g}, 114 \mathrm{mmol})$ was prepared in a $200-\mathrm{mL}$ one-necked round-bottom flask, and placed in an ice-water bath. Thereupon, 3-chloropropanol (8.4 mL, $101 \mathrm{mmol}$ ) was added dropwise, and stirred for $16 \mathrm{~h}$ at ambient temperature. After quenching the reaction by adding distilled water, the organic layer was collected and dried by sodium sulfate, after washing with water and with brine. 3-Chloropropoxy-tert-butyldimethylsilane (20 g, $97.7 \mathrm{mmol})$ was recovered after evaporating the solvent. Next, an acetone solution (100 $\mathrm{mL})$ of the obtained 3-chloropropoxy-tert-butyldimethylsilane $(5.4 \mathrm{~g}, 26.0 \mathrm{mmol})$ was placed in a $200 \mathrm{~mL}$ single-necked flask, and was subjected to the reaction with sodium iodide ( $25 \mathrm{~g}, 167$ 
mmol) by heating to reflux for $16 \mathrm{~h}$. After removing the solvents under reduced pressure, ethyl acetate was added to the mixture to form the organic layer, which was subsequently washed with distilled water and with brine, and was dried over anhydrous sodium sulfate. The solution was then filtered and the solvent was removed by the evaporation. The product, 3-iodopropoxy-tert-butyldimethylsilane $(6.3 \mathrm{~g}, 21.0 \mathrm{mmol})$, was obtained after the flash chromatography with silica gel by hexane / dichloromethane $=9 / 1$ (vol./vol.) as an eluent.

The obtained 3-iodopropoxy-tert-butyldimethylsilane was employed to prepare a hydroxyl-protected propyl lithium initiator according to the reported procedure. ${ }^{1,2}$ Thus a mixture solution of pentane $(2.9 \mathrm{~mL})$ and diethylether $(1.0 \mathrm{~mL})$ containing 3-iodopropoxy-tert-butyldimethylsilane $(0.42 \mathrm{~mL}, 1.8 \mathrm{mmol})$ was prepared in a $50 \mathrm{~mL}$ two-necked flask, dried in prior using a heat gun, under nitrogen, and placed in a dry ice acetone bath. Thereupon, a prescribed amount of tert-butyllithium (1.8 mol / L pentane solution, 2.1 $\mathrm{mL}, 3.8 \mathrm{mmol}$ ) was added dropwise under stirring, and the stirring was continued further for 0.5 h. The reaction was allowed to proceed for $2 \mathrm{~h}$ at room temperature, to form white precipitates. The supernatant portion was employed as an initiator solution for the polymerization of styrene.

The polymerization of styrene and the end-capping reaction of the resulted polystyrene was performed as follows. ${ }^{3-5}$ Thus, a solution of a weighed amount of styrene $(1.0 \mathrm{~mL})$ in tert-butylbenzene $(7.5 \mathrm{~mL})$ containing TMEDA $(0.10 \mathrm{~mL})$ was prepared in a $50 \mathrm{~mL}$ two-necked 
flask, dried in prior using a heat gun, and was placed in an ice bath. The polymerization reaction was allowed to proceed for $0.5 \mathrm{~h}$ after adding the hydroxyl-protected propyl lithium initiator solution at once. A prescribed amount of diphenylethylene $(0.10 \mathrm{~mL})$ was then added into the polymerization solution to continue the stirring for $15 \mathrm{~min}$, and 4-bromoorthobutylate $(0.070 \mathrm{~mL})$ was subsequently added to complete the end-capping reaction under the stirring for further $2 \mathrm{~h}$. The reaction mixture was then added dropwise into methanol to recover the crude products, which was purified by reprecipitation from chloroform/methanol system. The telechelic polystyrene having a tert-butyldimethylsilyloxyl and an orthoester end groups was thus obtained in the yield of $1.1 \mathrm{~g}(\mathrm{Mn}(\mathrm{GPC})=3.7 \mathrm{kDa})$.

Finally, the deprotection of tert-butyldimethylsilyl group on the hydroxyl unit and the conversion of orthoester end group into methyl carboxylate unit was carried out simultaneously to give a telechelic polystyrene having a hydroxyl and a methyl carboxylate end groups (PS-1) by the following procedure. ${ }^{5}$ Thus, into a THF solution $(10 \mathrm{~mL})$ containing a weighed amount of the polystyrene precursor having a tert-butyldimethylsilyl and an orthoester end groups ( 0.86 $\mathrm{g})$, and $0.50 \mathrm{~mL}$ of aqueous $\mathrm{HCl}(12 \mathrm{M})$ was added to stir for $2 \mathrm{~h}$ at ambient temperature. The reaction mixture was then added dropwise into methanol to recover the crude product, which was purified by reprecipitation from chloroform/methanol system. The telechelic polystyrene having a hydroxyl and a methyl carboxylate end groups (PS-1) was thus obtained in the yield of 
$0.88 \mathrm{~g}$.

${ }^{1} \mathrm{H}$ NMR $\left(\mathrm{CDCl}_{3}\right.$ ) (Figure 1, top): $\delta: \quad 0.57-2.69\left(\mathrm{~m}, \mathrm{CH}_{2} \mathrm{CHC}_{6} \mathrm{H}_{5}\right), 3.43\left(\mathrm{~m}, 2 \mathrm{H}, \mathrm{CH} \mathrm{H}_{2} \mathrm{OH}\right), 3.54$

(s, $\left.3 \mathrm{H}, \mathrm{CH}_{3} \mathrm{OCO}\right), 6.19-8.30\left(\mathrm{~m}, \mathrm{CH}_{2} \mathrm{CHC}_{6} H_{5}\right)$

Synthesis of a telechelic poly(THF) having a 3,3-dimethyl- $N$-phenylpiperridinium salt and a benzoic acid groups (PTHF-1c)

A zwitterionic poly(THF) having a pair of a 3,3-dimethyl- $N$-phenylpiperridinium and a benzoic acid end groups was prepared by the similar procedure described for the preparation of

PTHF-1b, but with 3,3-dimethyl- $N$-phenylpiperridine as an end-capping reagent.

${ }^{1} \mathrm{H}$ NMR $\left(\mathrm{CDCl}_{3}\right)$ (Figure S8, top): $\delta: 1.08\left(\mathrm{~s}, 6 \mathrm{H}, \mathrm{NCH}_{2} \mathrm{C}\left(\mathrm{CH}_{3}\right)_{2}\right), 1.57-1.68\left(\mathrm{~m}, \mathrm{CH}_{2} \mathrm{CH}_{2} \mathrm{O}\right)$, 3.74-4.47 (m, 6H, NCH $\left.\mathrm{N}_{2}\right), 4.58\left(\mathrm{~d}, 2 \mathrm{H}, 10.6 \mathrm{~Hz}, \mathrm{Ar}-\mathrm{CH}_{2} \mathrm{O}\right), 7.45(\mathrm{dd}, 2 \mathrm{H}, \mathrm{J} 1=22.7 \mathrm{~Hz}, \mathrm{~J} 2=8.1$ $\mathrm{Hz}, \mathrm{Ar}-\mathrm{H}$ meta to $\left.\mathrm{CO}_{2} \mathrm{H}\right), 7.53-7.63(\mathrm{~m}, 5 \mathrm{H}, \mathrm{Ar}-H), 8.08(\mathrm{dd}, 2 \mathrm{H}, \mathrm{J} 1=25.5 \mathrm{~Hz}, \mathrm{~J} 2=8.2 \mathrm{~Hz}$, Ar-H ortho to $\left.\mathrm{CO}_{2} \mathrm{H}\right)$

Synthesis of a telechelic poly(THF) having a 3,3-dimethyl- $N$-phenylpiperridinium cation and a benzoate anion groups (PTHF-Ic).

The obtained poly(THF) having 3,3-dimethyl- $N$-phenylpiperridinium salt group and a benzoic acid group, PTHF-1c, was subsequently treated with DBU to allow the deprotonation 
from a benzoic acid group to form a zwitterionic poly(THF) having a 3,3-dimethyl- $N$-phenylpiperridinium salt group and a benzoate group, PTHF-Ic.

${ }^{1} \mathrm{H}$ NMR $\left(\mathrm{CDCl}_{3}\right)$ (Figure $\mathrm{S} 8$, middle): $\delta: 1.08\left(\mathrm{~s}, 6 \mathrm{H}, \mathrm{NCH}_{2} \mathrm{C}\left(\mathrm{CH}_{3}\right)_{2}\right), 1.57-1.68(\mathrm{~m}$, $\left.\mathrm{CH}_{2} \mathrm{CH}_{2} \mathrm{O}\right), 4.07-4.38\left(\mathrm{~m}, 6 \mathrm{H}, \mathrm{NCH}_{2}\right), 4.53\left(\mathrm{~d}, 2 \mathrm{H}, 10.6 \mathrm{~Hz}, \mathrm{Ar}-\mathrm{CH}_{2} \mathrm{O}\right), 7.45(\mathrm{~m}, 2 \mathrm{H}, \mathrm{Ar}-\mathrm{H}$ meta to $\left.\mathrm{CO}_{2}\right), 7.53-7.63(\mathrm{~m}, 5 \mathrm{H}, \mathrm{Ar}-\mathrm{H}), 8.09\left(\mathrm{~m}, 2 \mathrm{H}, \mathrm{Ar}-\mathrm{H}\right.$ ortho to $\left.\mathrm{CO}_{2}\right)$

Polymer cyclization with a telechelic poly(THF) having a

\section{3,3-dimethyl- $N$-phenylpiperridinium cation and a benzoate anion groups (PTHF-Ic).}

A THF solution $(350 \mathrm{~mL})$ containing a weighed amount $(65 \mathrm{mg})$ of a zwitterionic poly(THF) having a pair of a 3,3-dimethyl- $N$-phenylpiperridinium and a benzoate end groups, PTHF-Ic, was prepared by stirring for $1 \mathrm{~h}$ in a $0.5 \mathrm{~L}$ two-neck round-bottom flask, and was heated to reflux for $4 \mathrm{~h}$. Thereafter, the solution was condensed by evaporating the solvent, and was subjected to a silica gel column chromatography with acetone/hexane (1/2 in vol) mixture as an eluent. The cyclic poly(THF) product, PTHF-IIc, was finally isolated after the reprecipitation into water cooled at $0{ }^{\circ} \mathrm{C}$ in the yield of $30 \mathrm{mg}$.

${ }^{1} \mathrm{H}$ NMR $\left(\mathrm{CDCl}_{3}\right)$ (Figure S8, bottom): $\delta: \quad 1.57-1.71\left(\mathrm{~m}, \mathrm{CH}_{2} \mathrm{CH}_{2} \mathrm{O}\right), 3.35-3.53\left(\mathrm{~m}, \mathrm{CH}_{2} \mathrm{CH}_{2} \mathrm{O}\right)$, $4.34\left(\mathrm{t}, 2 \mathrm{H}, J=6.4 \mathrm{~Hz}, \mathrm{CO}_{2} \mathrm{CH}_{2}\right), 4.55\left(\mathrm{~s}, 2 \mathrm{H}, \mathrm{Ar}_{-} \mathrm{CH}_{2} \mathrm{O}\right), 7.40(\mathrm{~d}, 2 \mathrm{H}, J=8.4 \mathrm{~Hz}$, Ar-H meta to $\left.\mathrm{CO}_{2}\right), 8.01\left(\mathrm{~d}, 2 \mathrm{H}, J=8.1, \mathrm{Ar}-\mathrm{H}\right.$ ortho to $\left.\mathrm{CO}_{2}\right)$ 


\section{REFERENCES}

1. Ashby, E. C.; Pham, T. N., Single Electron Transfer in Metal Halogen Exchange. The Reaction of Organolithium Compounds with Alkyl Halides, J. Org. Chem., 1987, 52, $1291-1300$.

2. Zhou, S.; Jia, Y., Total Synthesis of (-)-Goniomitine. Org. Lett., 2014, 16, 3416-3418.

3. Hirao, A.; Nagahama, H.; Ishizone, T.; Nakahama, S., Synthesis of Polymers with Carboxy End Groups by Reaction of Polystyryl Anions with 4-Bromo-1,1,1-trimethoxybutane, Macromolecules, 1993, 26, 2145-2150.

4. Ji, H.; Nonidez, W. K.; Advincula, R. C.; Smith, G. D.; Kilbey, S. M.; Dadmun, M. D.; Mays, J. W., MALDI-TOF MS Characterization of Carboxyl-End-Capped Polystyrenes Synthesized Using Anionic Polymerization, Macromolecules, 2005, 38, 9950-9956.

5. Sugiyama, K.; Oie, T.; El-Magd A. A.; Hirao, A., Synthesis of Well-Defined (AB) Multiblock Copolymers Composed of Polystyrene and Poly(methyl methacrylate) Segments Using Specially Designed Living AB Diblock Copolymer Anion, Macromolecules, 2010, 43, $1403-1410$. 


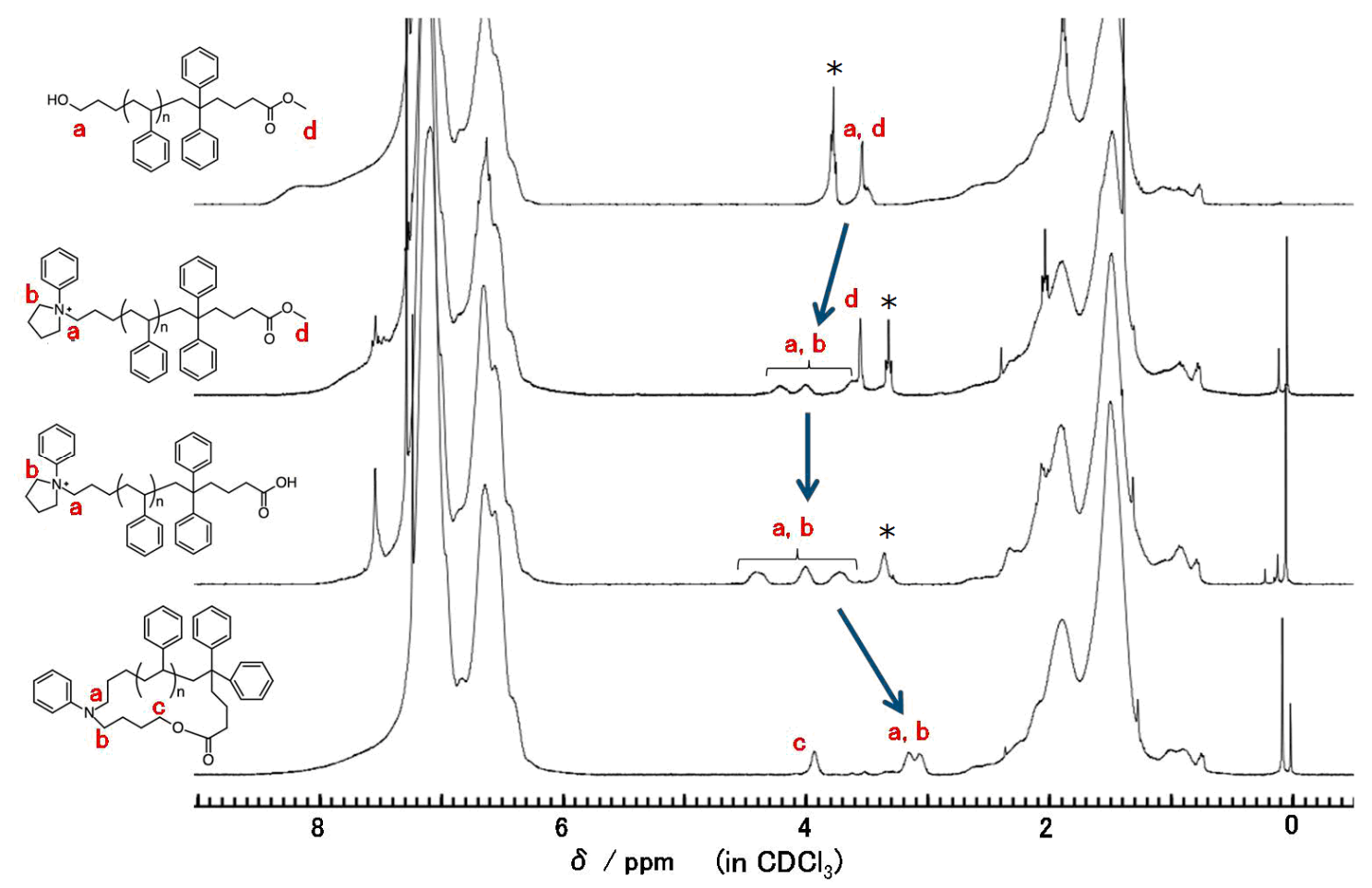

Figure S1: $300 \mathrm{MHz}{ }^{1} \mathrm{H}$ NMR spectra of a series of polystyrene precursors, PS-1, PS-2b, PS-3b and the ESA-CF polymer cyclization product, PS-IIb. $\left(\mathrm{CDCl}_{3}, 40{ }^{\circ} \mathrm{C}, *\right.$ denotes solvent peaks) 

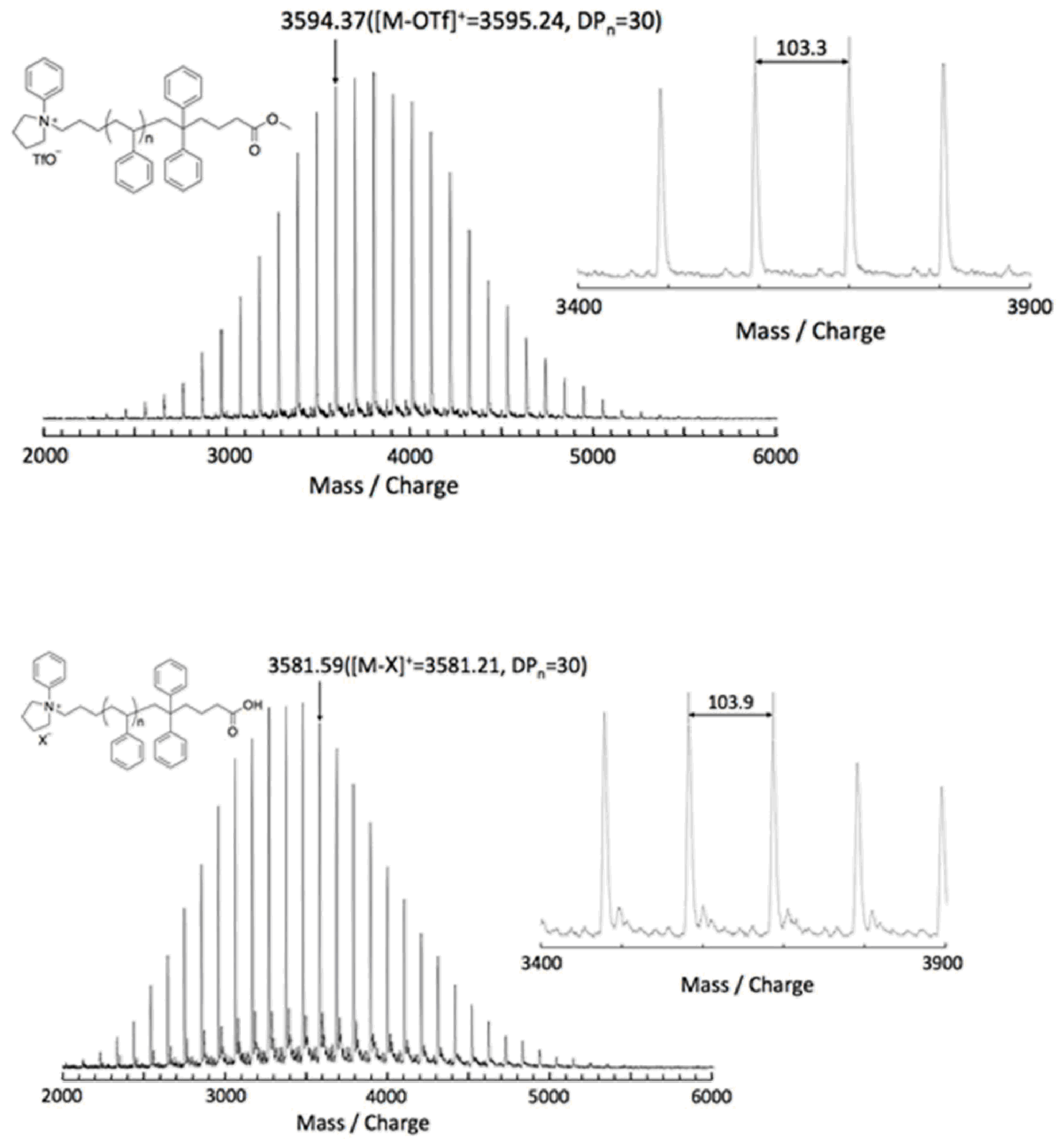

Figure S2: MALDI-TOF mass spectra of a series of polystyrene precursors, (top) PS-2b and (bottom) PS-3b. (Linear mode, matrix: 1,1,4,4-tetraphenyl-1,3-butadiene (TPB). $\mathrm{DP}_{\mathrm{n}}$ denotes the number of monomer units in the product.) 

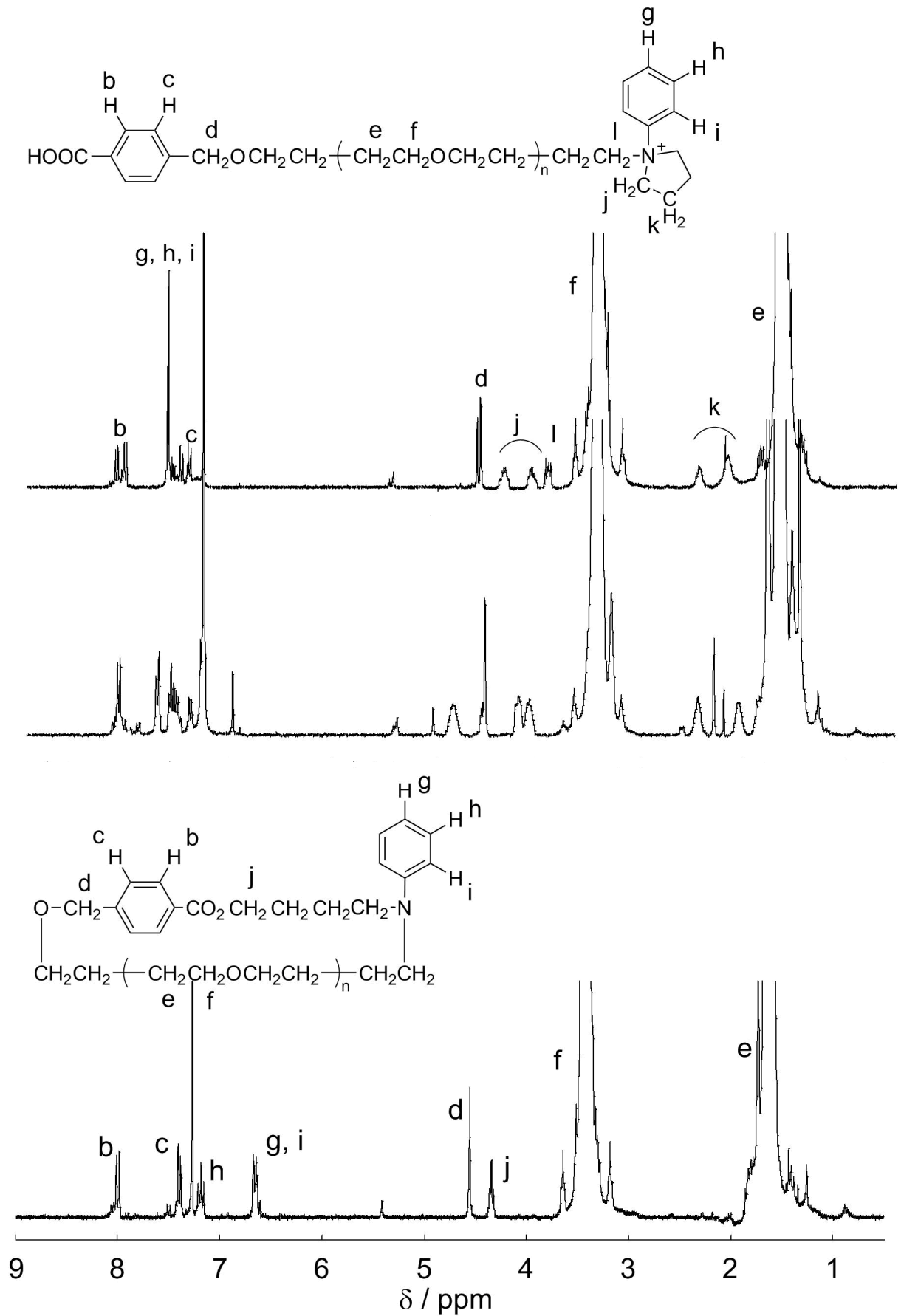

Figure S3: $300 \mathrm{MHz}{ }^{1} \mathrm{H}$ NMR spectra of (top) PTHF-1b, (middle) the deprotonation product by DBU treatment, PTHF-Ib and (bottom) the polymer cyclization product, PTHF-IIb. $\left(\mathrm{CDCl}_{3}\right.$, $40{ }^{\circ} \mathrm{C}$ ) 


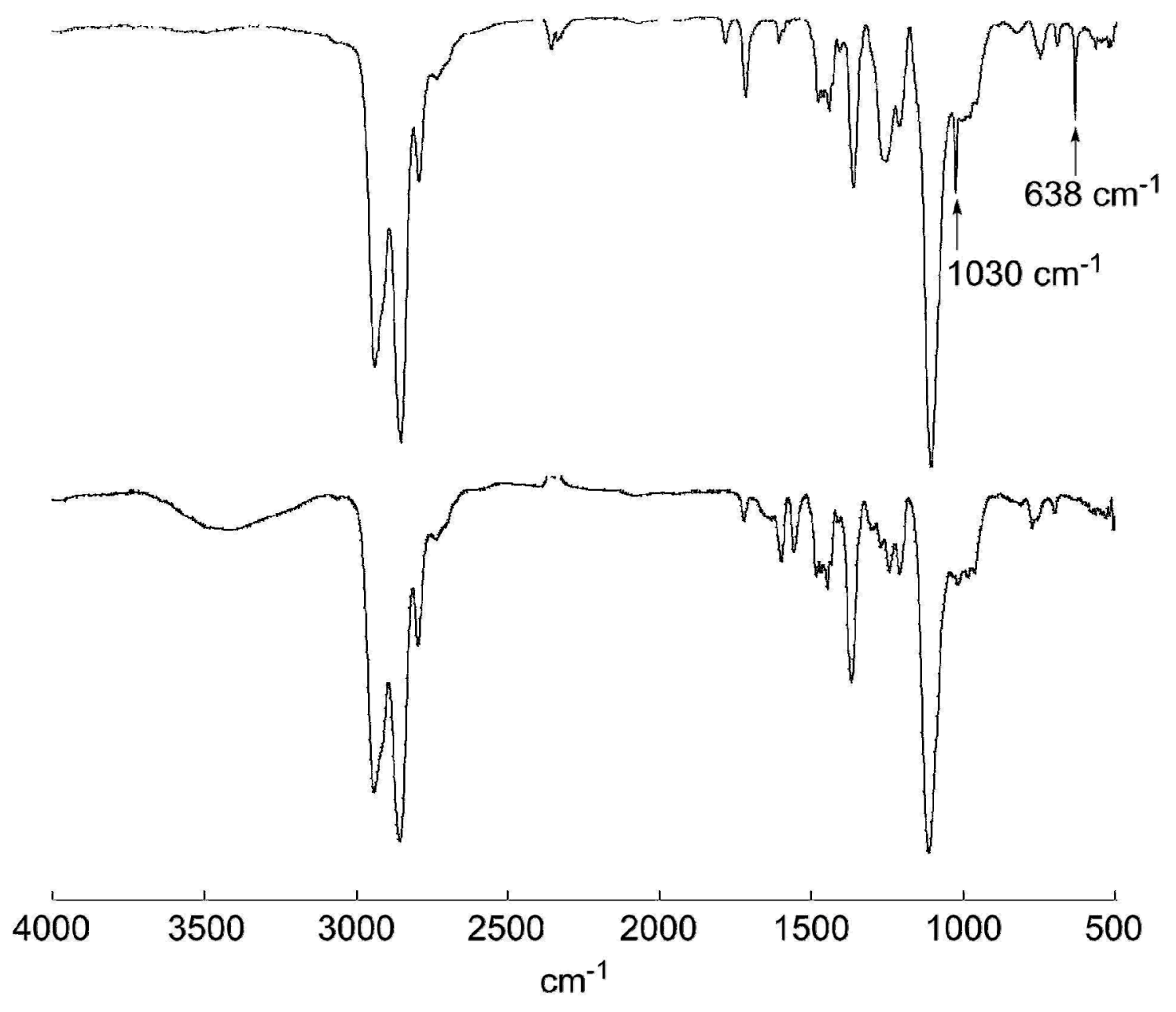

Figure S4: IR spectra of (top) PTHF-1b and (bottom) the deprotonation product PTHF-Ib by DBU treatment. 


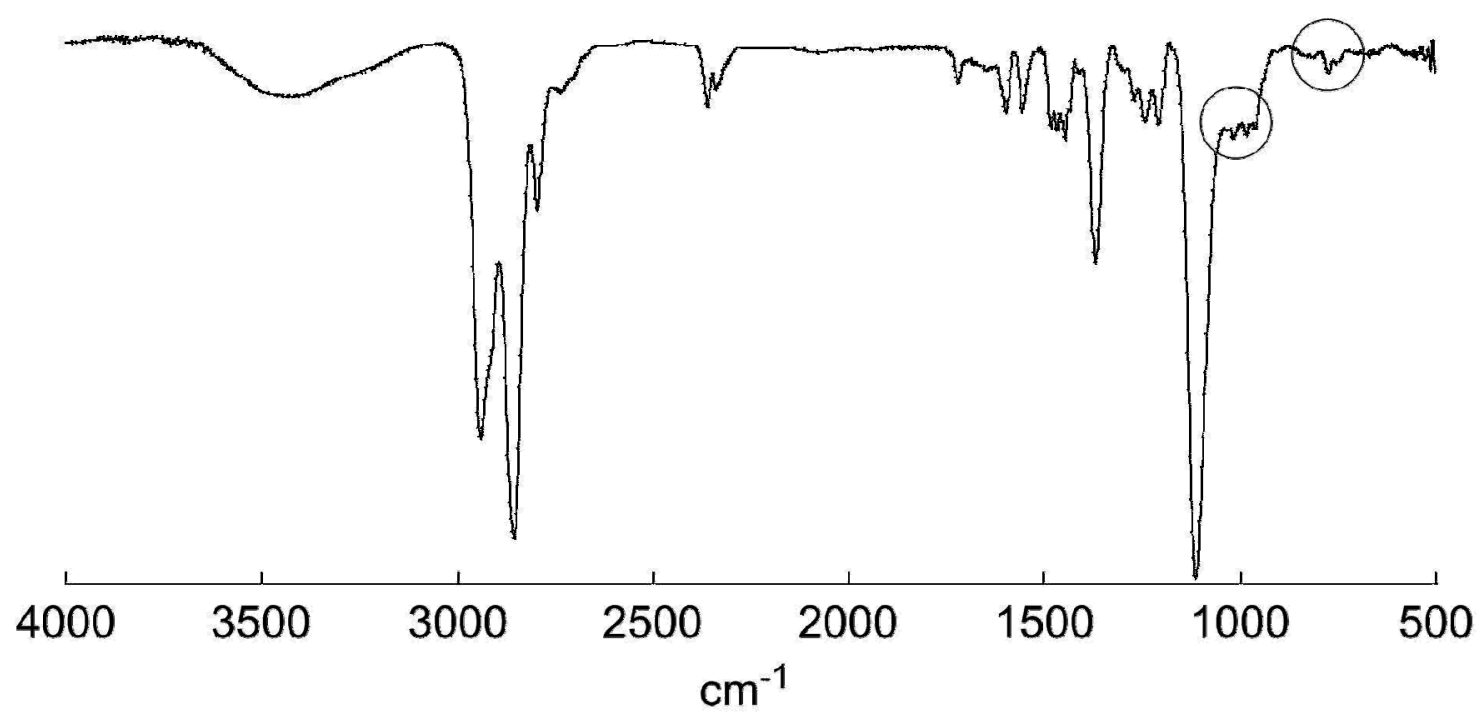

Figure S5: An IR spectrum of PTHF-Ia produced by the deprotonation in situ. 


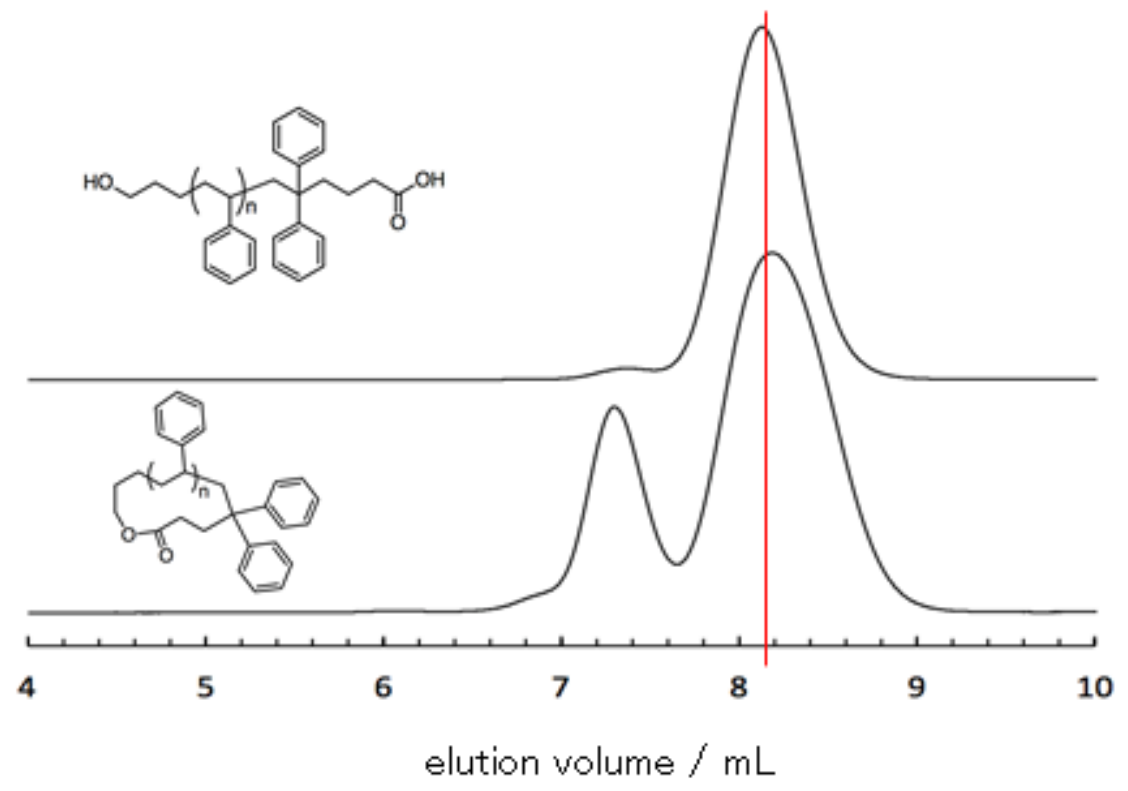

Figure S6: SEC traces of (top) a telechelic polystyrene having a hydroxyl and carboxylic acid groups, and (bottom) the polymer cyclization product obtained by a macrolactonization catalyst. (THF as an eluent, $1.0 \mathrm{~mL} / \mathrm{min}$ ) 


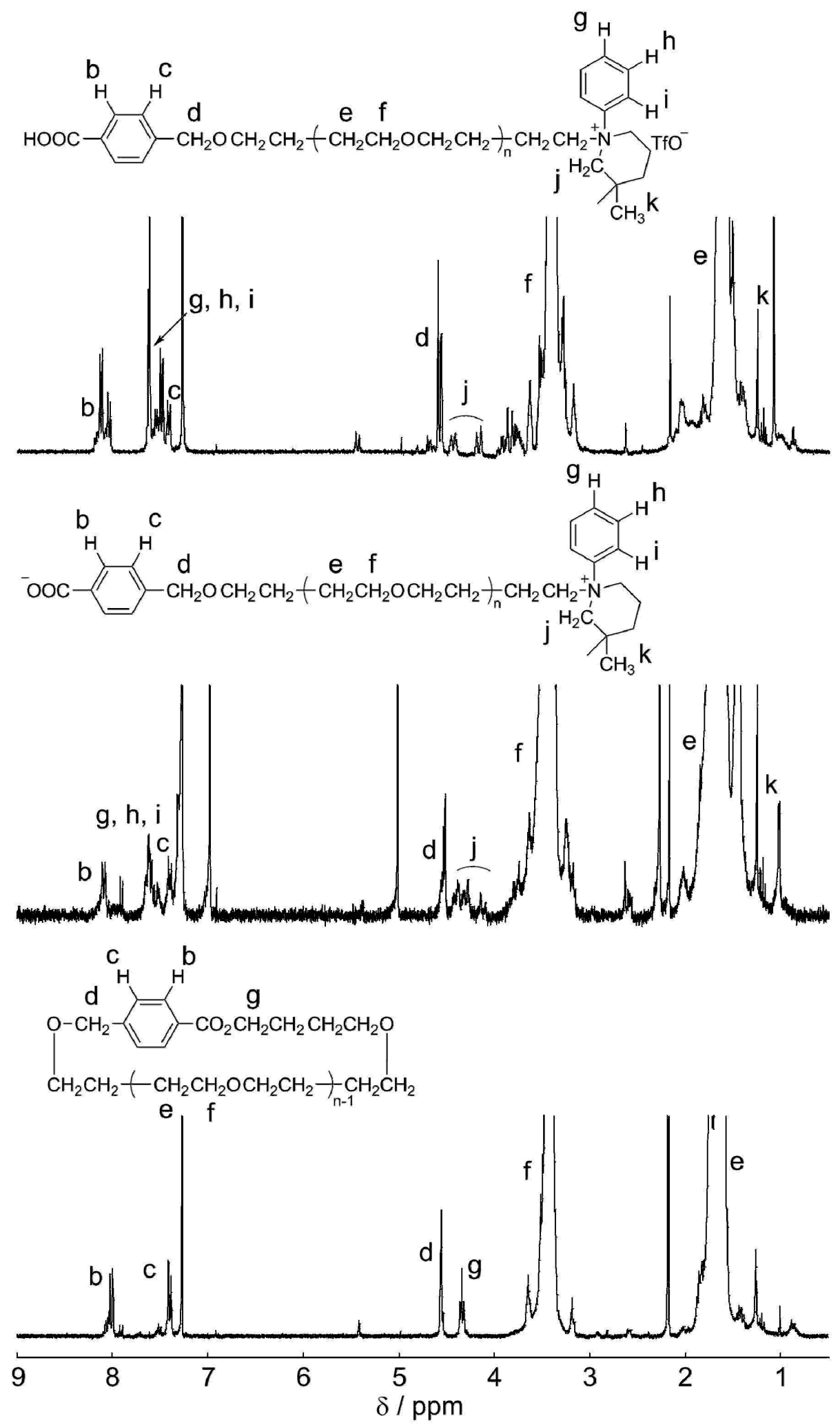

Figure S7: $300 \mathrm{MHz}{ }^{1} \mathrm{H}$ NMR spectra of (top) PTHF-1c, (middle) PTHF-Ic and (bottom) PTHF-IIc. $\left(\mathrm{CDCl}_{3}, 40{ }^{\circ} \mathrm{C}\right)$ 


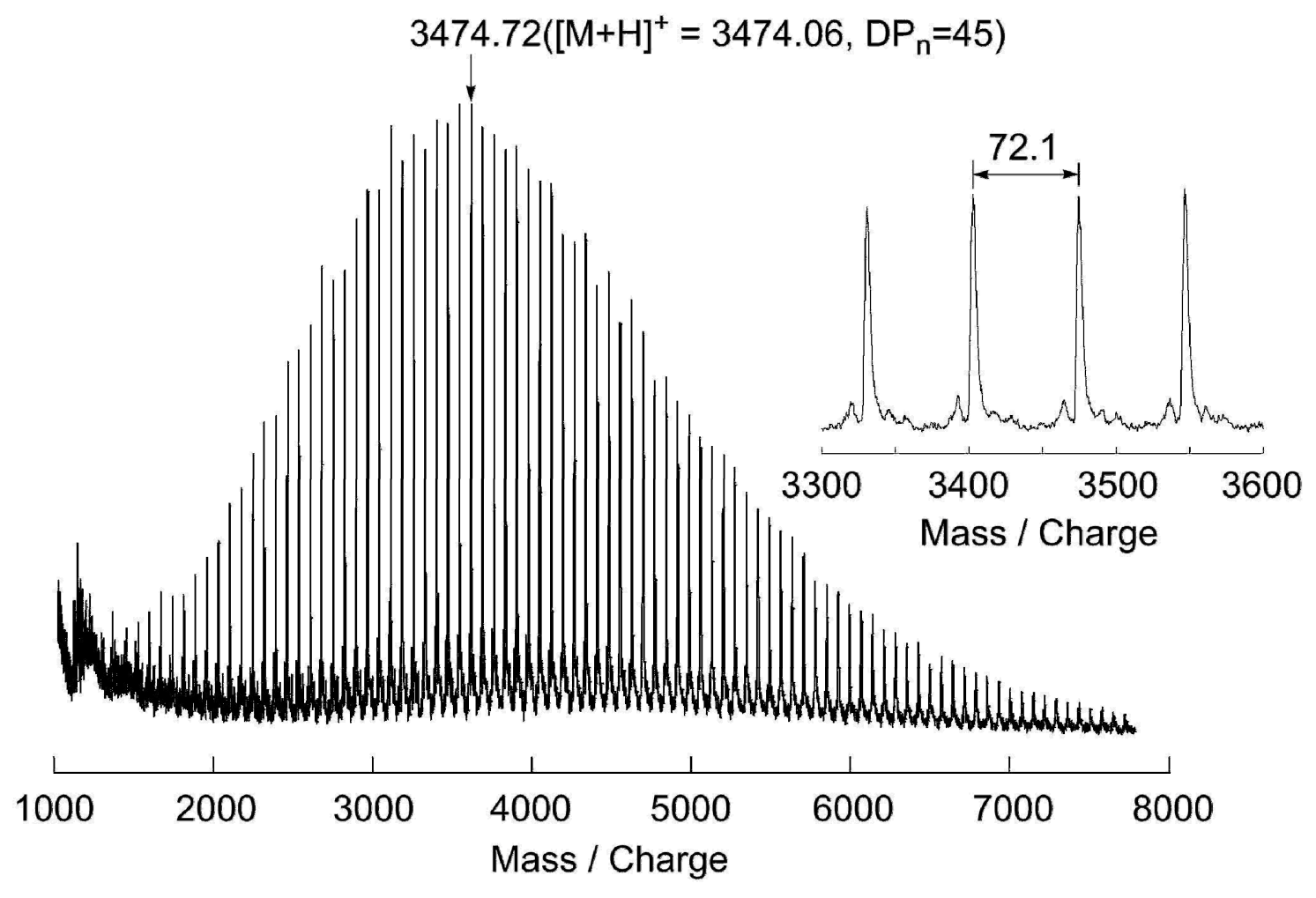

Figure S8: A MALDI-TOF mass spectrum of PTHF-IIc. (Linear mode, matrix: dithranol with sodium trifluoroacetate. $\mathrm{DP}_{\mathrm{n}}$ denotes the number of monomer units in the product.) 


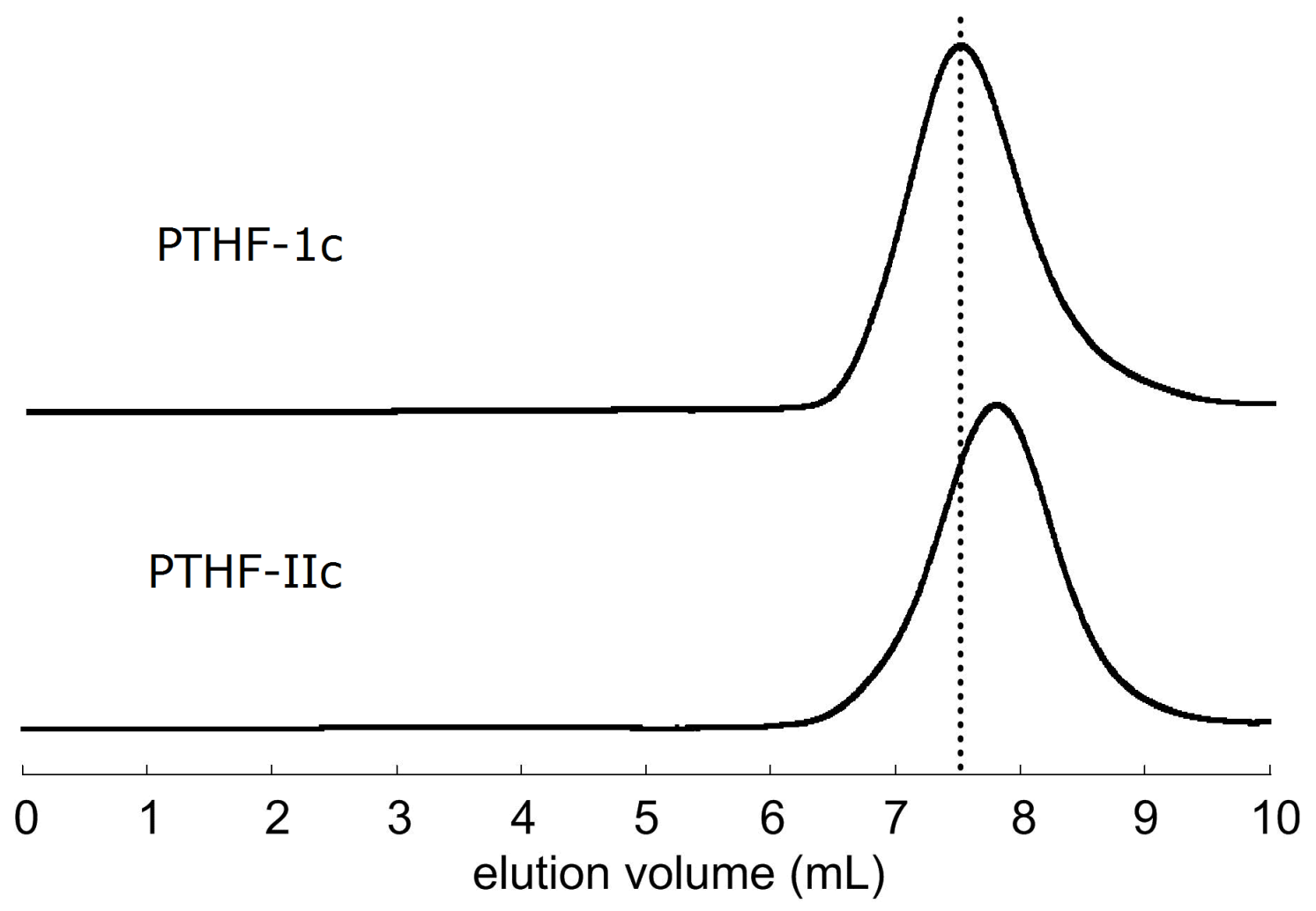

Figure S9: SEC traces of (top) the covalently converted product from PTHF-1c by benzoate anion, and (bottom) the polymer cyclization product, PTHF-IIc. (THF as an eluent, 1.0 $\mathrm{mL} / \mathrm{min})$ 

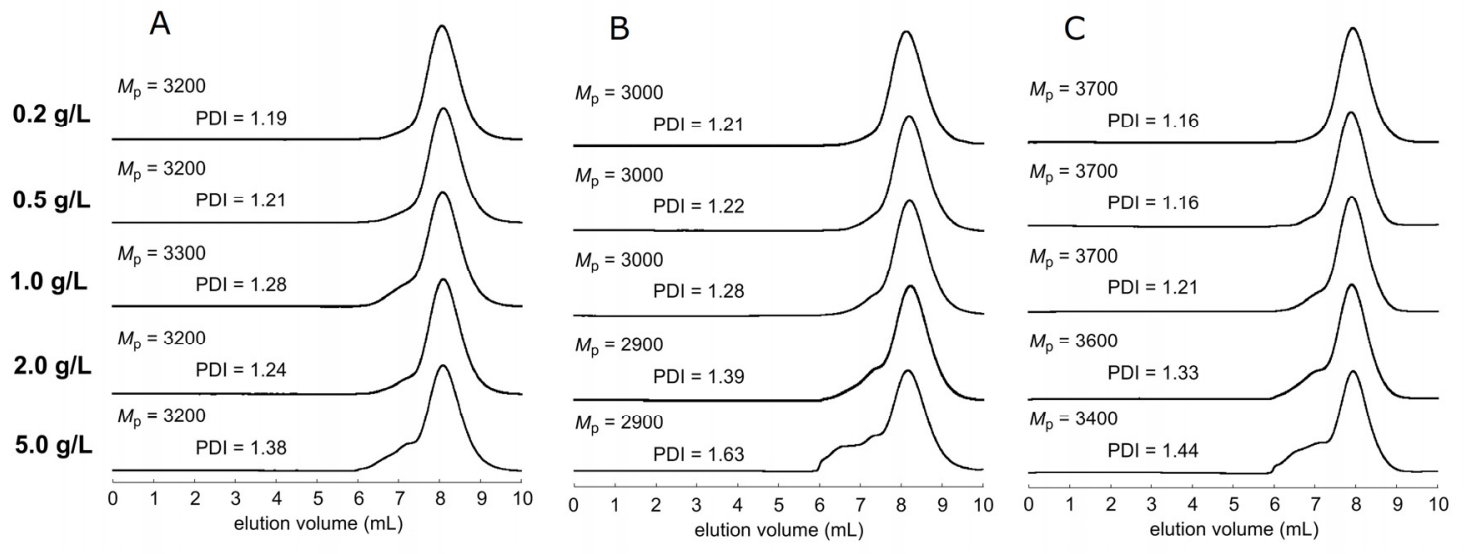

Figure S10: SEC traces of the cyclic poly(THF)s obtained at different dilutions; (A) poly(THF)-IIa, (B) poly(THF)-IIb obtained by the unimolecular ESA-CF process, and (C) Cyclic poly(THF)s obtained by the bimolecular ESA-CF process using a telechelic poly(THF) having $N$-phenylpyrrolidinium end groups. (THF as an eluent, $1.0 \mathrm{~mL} / \mathrm{min}$ ) 